\title{
Norois
}

Environnement, aménagement, société

$211 \mid 2009 / 2$

Eau, pêche, tourisme rural, conflits d'usage

\section{Salomon (J.-N.) - Géomorphologie sous-marine et littorale}

Pessac, Presses Universitaires de Bordeaux, coll. « Scieteren », 387 p.

\section{Yannick Lageat}

\section{(2) OpenEdition}

\section{Journals}

Édition électronique

URL : http://journals.openedition.org/norois/2906

DOI : $10.4000 /$ norois. 2906

ISBN : 978-2-7535-1559-8

ISSN : 1760-8546

\section{Éditeur}

Presses universitaires de Rennes

\section{Édition imprimée}

Date de publication : 1 octobre 2009

Pagination : 81-83

ISBN : 978-2-7535-0937-5

ISSN : 0029-182X

\section{Référence électronique}

Yannick Lageat, « Salomon (J.-N.) - Géomorphologie sous-marine et littorale », Norois [En ligne], 211 2009/2, mis en ligne le 28 octobre 2009, consulté le 23 septembre 2020. URL : http:// journals.openedition.org/norois/2906; DOl : https://doi.org/10.4000/norois.2906 


\title{
COMPTE RENDU BIBLIOGRAPHIQUE
}

\author{
SAlomon (J.-N.), 2008. - Géomorphologie sous-marine et littorale, Pessac, Presses \\ Universitaires de Bordeaux, coll. « Scieteren », 387 p.
}

Dans une collection qu'il dirige et qui a déjà accueilli son remarquable Précis de Karstologie en 2007, JeanNoël Salomon, Professeur émérite à l'Université de Bordeaux III, s'est risqué à publier, sous un titre voisin, une actualisation de l'ouvrage fondateur d'André Guilcher de 1954 qui avait bénéficié d'une traduction anglaise, mais n'avait malencontreusement jamais été réédité en français. Le défi n'était pas mince puisque le regretté Roland Paskoff nous a laissé en héritage un manuel de géomorphologie côtière qui fait autorité, tandis que la géomorphologie sous-marine est désormais très largement prise en charge par les géologues, Jean-René Vanney n'ayant malencontreusement pas fait d'émules.

L'ouvrage n'est pas sans défauts. Il renferme un nombre d'erreurs factuelles dont les plus surprenan-

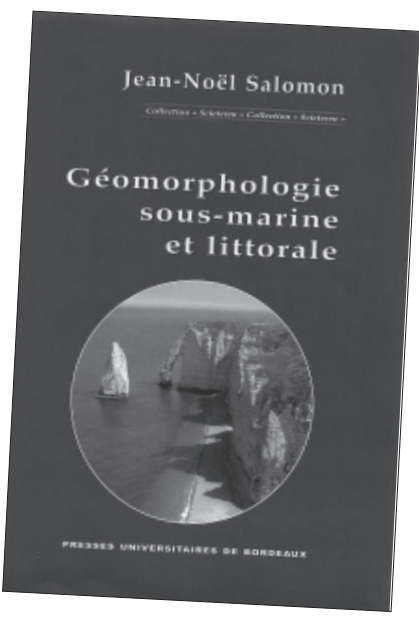
tes concernent l'évolution du niveau marin : il n'est pas vrai que, «l'Antarctique n'était pas constitué lors des premières glaciations » et que, de ce fait, « les premières transgressions du Quaternaire ancien ont sans doute été plus faibles que celles du Quaternaire récent» (p. 101). Rappelons, d'une part, que cet inlandsis recouvrait le continent dès le Miocène, et que le niveau marin ne s'est pas élevé jusqu’à $+15 \mathrm{~m}$ au cours de l'Éémien et même $+30 \mathrm{~m}$ durant le pénultième interglaciaire. D’ailleurs, René Battistini, qui a préfacé l'ouvrage, fut l'un des premiers, parmi les géomorphologues français, à émettre des doutes sur la réalité du dogme eustatique qui triomphait encore au cours des années 1960.

On peut s'étonner que figurent, parmi les facteurs de l'érosion littorale, les grands courants océaniques (dont El Niño), que les marées soient désignées comme « des sortes de très grandes vagues » (p. 123), que les Cliffs of Moher soient rangées dans la famille des mégafalaises (p. 158), que processus de glissement et de solifluxion soient confondus, notamment à propos de l'évolution de la falaise des Vaches Noires (p. 162), que le musoir soit désigné comme une flèche (p. 222), et que, dans l'estuaire de la Gironde, l'apport fluviatile ne soit estimé annuellement qu'à un millier de tonnes de sédiments, alors que le Rhin en apporterait 5 millions à la mer du Nord (p. 261)...

Le plan est, par ailleurs, déroutant. L'ouvrage, structuré en sept parties, aurait pu être organisé avec plus de rigueur : pourquoi avoir dissocié l'examen des fonds océaniques (chapitre 2) de l'origine de l'océan Mondial (qui le précède)? Pourquoi avoir consacré un chapitre, déconnecté de ceux qui l'encadrent, aux caractères de l'eau de mer (chapitre 3) ? Quel est le rapport qu'entretiennent les plaines d'accumulation glaciaire avec les côtes rocheuses (chapitre 5) ? Pourquoi avoir séparé l'étude des estuaires (chapitre 7) de celle des deltas (chapitre 8), alors que, selon l'auteur, il existe entre eux une filiation depuis les formes initiales que sont les rias (p. 252 et 256), etc. ?

Il n'est pas sûr que Jean-Noël Salomon disposait sur tous les littoraux de la riche connaissance qu'il a engrangée sur les modes et formes de dissolution des roches carbonatées. De fait, les pages les plus convaincantes concernent les littoraux tropicaux 
et les côtes basses sableuses, grâce aux recherches qu'il a menées dans le Sud-Ouest malgache, à la faveur des travaux approfondis qui ont accompagné l'élaboration de sa thèse de doctorat d'État, et sur les côtes aquitaines et charentaises qu'il a arpentées depuis sa nomination à Bordeaux. C'est là que réside le meilleur de l'ouvrage.

Tout au long du chapitre 6 consacré aux plages, l'auteur montre très clairement que des matériaux de la granulométrie des sables (nonobstant un lapsus calimi au bas de la page 191) vont se distribuer selon des profils topographiques, des structures internes, des formes de surface dont l'évolution constante nourrit une analyse approfondie des plages, avant-plages et systèmes dunaires. On ne s'étonnera pas qu'une attention particulière ait été prêtée aux baïnes si caractéristiques du système barres-sillons de la côte aquitaine. Les intéressants développements sur les techniques de défense contre la mer (p. 140-146) auraient avantageusement trouvé leur place à la fin de ce chapitre.

Le lecteur appréciera aussi la présentation des marais maritimes - que l'auteur aurait pu éviter d'associer aux seuls estuaires dans le septième chapitre -, témoignant de sa parfaite connaissance des substrats les plus aptes à l'installation et au développement des mangroves, ainsi que celle des deltas dont la morphologie de compromis fait l'objet du chapitre 8 où sont exposées leurs classifications fondées sur la taille, sur les processus dynamiques et, de manière moins attendue, sur l'appartenance zonale.

Plus convaincants encore sont les pages consacrées au «monde récifal », et le dernier chapitre se nourrit d'une connaissance intime de la morphologie des récifs que l'auteur aborde à partir de l'exemple, il est vrai démonstratif, du Grand Récif de Tuléar (Toliary), avant d'en proposer un typologie et d'en retracer la genèse et l'évolution, en distinguant soigneusement les récifs « de plate-forme » de ceux « de plein océan ». La figure de la page 341, dont on eût apprécié qu'elle fît plus explicitement référence à des publications précises, et non point à des « auteurs australiens " anonymes, résume remarquablement les évolutions possibles de ces biohermes, qui se révèlent être d'excellents enregistreurs de l'environnement, dès lors que leur croissance est permise par des facteurs hydrologiques, bathymétriques et biologiques.

Comme trop souvent dans les typologies côtières, «les côtes rocheuses et à falaises ", auxquelles est consacré le chapitre 5, sont les parentes pauvres, même si, après avoir sacrifié à la théorie classique qui fait de la mise en surplomb d'une masse rocheuse le mode de retrait privilégié des escarpements côtiers, l'auteur concède que « les actions continentales sont parfois plus importantes que les actions marines » (p. 164)... Sont curieusement confondues côtes découpées et côtes de dénudation : si les premières résultent de la simple ingression de la mer flandrienne, les secondes supposent l'exhumation ou la révélation d'un substrat rocheux. Il n'est pas judicieux de dénier aux escarpements côtiers de Saint-Jean-de-Luz le nom de «falaises » (p. 161) et d'accepter que soient ainsi désignés les profils, évidemment temporaires, taillés dans des sables secs (p. 162), ou de choisir comme exemple de recul de ces abrupts littoraux la disparition - au XIV ${ }^{\mathrm{e}}$ siècle et non au XIX $\mathrm{X}^{\mathrm{e}}$ siècle - du port de Chef-du-Caux (p. 164), puisqu'il se localisait plus probablement sur une flèche de galets construite dans le prolongement de la falaise de craie du Cap de la Hève !

En définitive, l'ouvrage de Jean-Noël Salomon, que nous nous garderons de définir comme un manuel, est une œuvre très personnelle illustrée par de remarquables photographies collectées sur différents terrains, de la Patagonie argentine à l'île d'Okinawa, du Spitzberg à la Nouvelle-Zélande, de la mer des Antilles à la mer Noire... D'évidence trop personnelle! Elle n'aurait pas souffert que de fines observations fussent plus systématiquement confrontées à la bibliographie, il est vrai pléthorique. L'auteur se contente d'ailleurs d'une liste de quelque 80 références, dont le dixième dû à sa propre plume, et oublie quelques titres cités dans le texte (dont L. Schmied, M. Mainguet ou J.-P. Pinot). «Ce n'est pas assez de compter les expériences, écrivait Montaigne, il les faut 
poiser et assortir et les faut avoir digérées et alambiquées, pour en tirer les raisons et les conclusions qu'elles portent », et le Bordelais qu'est Jean-Noël Salomon aurait dû s'attacher à plus « frotter et limer (sa) cervelle contre celle d'autrui ».

Yannick LAGEAT 